\title{
DEVELOPING A FRAMEWORK FOR EVALUATING SPENT NUCLEAR FUEL MANAGEMENT OPTIONS FOR SOUTH AFRICA
}

\author{
V.G. Twala ${ }^{1}$, T. Auf der Heyde ${ }^{2}$, P.J. Bredell ${ }^{3}$ and L. Pretorius ${ }^{4}$ \\ ${ }^{1}$ Nuclear Fuel Department, Generation Division \\ Eskom, South Africa \\ vusi.twala@eskom.co.za \\ ${ }^{2}$ Department of Research and Innovation \\ University of Johannesburg, South Africa \\ taufderheyde@uj.ac.za \\ ${ }^{3}$ Nuclear Liabilities Management Department \\ Nuclear Energy Corporation of South Africa (Necsa) \\ pbredell@necsa.co.za \\ ${ }^{4}$ Department of Engineering and Technology Management \\ Graduate School of Technology Management \\ University of Pretoria, South Africa \\ leon.pretorius@up.ac.za
}

\begin{abstract}
The search for consensus on spent fuel management (SFM) strategies in the nuclear industry has become complex, not least in the South African context. This study identifies three SFM options: reprocessing-and-recycling, direct disposal, and indefinite storage. From the contentious issues surrounding the SFM options, a framework for evaluating the options and selecting a preferred SFM option for South Africa is proposed. It consists of evaluation criteria categorised into nine dimensions: technological, safety, environmental, proliferation, security, economic, sociopolitical, ethical, and institutional. The framework's comprehensiveness shows that SFM options have developed to a stage where South Africa can make an informed policy decision on the strategy it wishes to pursue.
\end{abstract}

\section{OPSOMMING}

Die soeke na eenstemmigheid rondom strategieë vir die hantering van verbruikte kernafvalbrandstof (SFM) is kompleks. Hierdie artikel identifiseer drie SFM-opsies: Herprosessering en herwinning, direkte verwydering, en onbepaalde berging. Vanuit die sensitiewe kwessies wat die SFM-opsies beinvloed, word 'n raamwerk ontwikkel waarmee 'n voorkeuropsie vir Suid-Afrika daargestel word. Die raamwerk bestaan uit evalueringskriteria wat in nege dimensies gerangskik word: tegnologies, veiligheid, omgewing, proliferasie, sekuriteit, ekonomies, sosio-polities, eties, en institusioneel. Die omvang van die raamwerk dui daarop dat SFM opsies tot so 'n stand ontwikkel het dat Suid Afrika 'n ingeligte beleidsbesluit kan neem oor die strategie wat hy sou wou volg.

${ }^{1}$ The author was enrolled for a D Phil (Engineering Management) degree in the Department Mechanical Engineering Science, University of Johannesburg. 


\section{INTRODUCTION}

The existence of radioactive waste (or 'radwaste') has become a problem afflicting the nuclear industry worldwide. The search for a social consensus on radwaste management strategies is proving to be one of the most complex challenges facing nuclear technological development. The categories of radwastes that are currently of greatest concern are spent nuclear fuel (SF) that is discharged from nuclear power reactors, and high level waste (HLW) arising from the reprocessing of SF, as they continue to accumulate in storage facilities around the world. The popular perception that there is no end solution to these growing inventories is denied by the nuclear industry, which claims that there are plans for managing and disposing of them [1], [2], [3].

Chief among the prevailing concerns is that SF from light-water reactors (LWRs) contains enriched uranium $(\mathrm{U})$ and plutonium $(\mathrm{Pu})$, a man-made radioactive element that is both an ingredient for nuclear weapons production and a potential fuel for power generation [1] - and a source of considerable health and environmental risks. Substantial work, however, continues to be done to generate solutions to the problem of SF. For instance, France and Japan have invested considerably in the development of partitioning and transmutation technology as a solution that reduces the radiotoxicity of SF and the volume of waste [4], [5]. The USA and Russia are engaged in a Pu disposal programme that is aimed at reducing inventories of $\mathrm{Pu}$ by burning it as mixed-oxide fuel in nuclear power reactors [6].

Alongside these has been an ongoing debate over the best approach for spent fuel management (SFM): whether it is better to dispose of it directly in deep geological formations, or to reprocess it to recover and recycle the $\mathrm{U}$ and $\mathrm{Pu}$, disposing only of the HLW from reprocessing. On the one hand, the USA abandoned reprocessing and opted for direct disposal as a way to avoid Pu proliferation. Sweden and Finland are also pursuing the direct disposal route because reprocessing proved to be an expensive option for these countries [1], [7], [8]. On the other hand, France, Russia and Japan are the leading countries in reprocessing and recycling for reasons of energy supply security [1], [3]. Countries that have chosen to reprocess are facing high costs and rising political controversies (e.g. Belgium and Germany - with some of their reprocessing contracts cancelled), while many of those that have chosen not to reprocess are facing significant political obstacles to providing adequate storage space for SF [6], [9], [10]. Currently, no country in the world operates a permanent deep geological repository (DGR) for either SF or HLW. As a result of considerable research undertaken to date, some believe sufficient knowledge exists to conclude that, for the long term, both SF and HLW can be finally disposed of safely in a DGR so that their care need not be transferred to and imposed on future generations [11].

South Africa also faces major decisions about the future management of SF generated from its nuclear power and research reactors. A national policy for radwaste management has been adopted by government - the Department of Minerals and Energy (DME) - to allow the South African nuclear power industry to investigate and develop alternative strategies for national SFM and disposal, and to generate quantifiable facts upon which an optimal/preferred solution and political decisions can be based [12]. This paper thus introduces a framework for evaluating 
SFM options in terms of the assessment criteria constituting the framework, which can then be used for selecting a preferred SFM option for the local nuclear power programme.

\section{SPENT FUEL MANAGEMENT AND AVAILABLE OPTIONS}

\subsection{Definition of 'spent fuel'}

Spent nuclear fuel, or simply spent fuel (SF), can be defined as irradiated fuel units or elements discharged from a nuclear reactor and not intended for further use in the reactor [13]. These elements are referred to as spent fuel assemblies (SFA). When SF is not intended to be reprocessed but is planned to be disposed of permanently in a geological repository, it is classified as high-level radioactive waste $(\mathrm{HLW})$. This category of waste includes vitrified radwaste from SF reprocessing. Both SF and HLW account for approximately $99 \%$ of the radioactivity produced during nuclear electricity generation [2].

When discharged at the end of its burnup cycle the SF contains uranium (U), plutonium $(\mathrm{Pu})$, fission products, and other actinides mostly in the form of oxides, but the exact composition depends upon various parameters (e.g., initial enrichment, initial composition, burnup, etc.) which differ considerably for the different types of reactors and even for the reactors within one type. Most nuclear power reactors utilise nuclear fuel slightly enriched in U-235 (between 3\% and 7\%), with the rest of it remaining as $\mathrm{U}-238$. After a cycle of irradiation in the reactor, however, the fuel content is roughly $0.8 \%$ of unburned U-235, $94.3 \%$ of U-238, and fission products and newly formed isotopes of heavy elements including approximately $2 \%$ of a mixture of Pu isotopes [13].

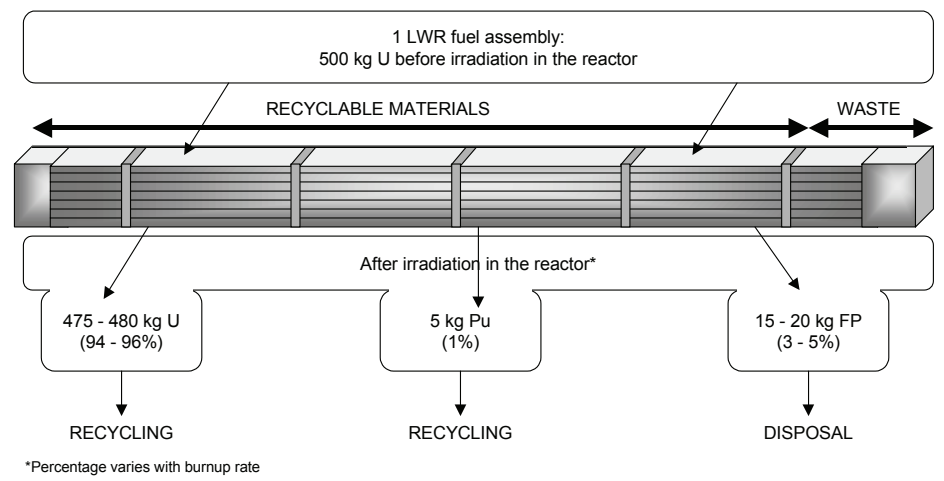

Figure 1: Composition of a light water reactor spent fuel assembly [14]

A schematic illustration of a light-water reactor (LWR) SFA, with its composition before and after irradiation in the reactor, is given in Figure 1 [14]. The figure shows the quantities of potentially recyclable material, $\mathrm{U}$ and $\mathrm{Pu}$, as well as fission products as final residues to be disposed of as HLW. 
The LWR SFA continues to emit heat during and long after discharge from the reactor owing to radioactive decay processes. For instance, one year after removal from the reactor, it generates heat at a rate of approximately $10 \mathrm{~kW}$ per ton heavy metal (HM) [15]. At first, the decrease of radioactivity and heat generation is very rapid as the short-lived radionuclides decay. As time passes, the radioactivity and heat-generation decrease more slowly, as they are controlled by the decay of the longer-lived radionuclides. As a result, upon discharge from the reactor the SFAs are transferred into water pools at the reactor site, where they will be stored for some years to facilitate decay of the initial intense radioactivity. The water both shields the emitted radiation and removes heat. Depending on the national policies, this SF could later be sent for continued storage away from the reactor, for reprocessing, or for final disposal underground.

\subsection{Spent fuel management policies (options)}

In the last four decades, considerable quantities of SF, HLW, and other radwastes have been generated worldwide through a wide range of separate activities of the so-called 'nuclear fuel cycle'. The nuclear fuel cycle describes each step from uranium $(U)$ mining through fuel utilisation in the reactor to waste disposal, as illustrated in Figure 2 [16].

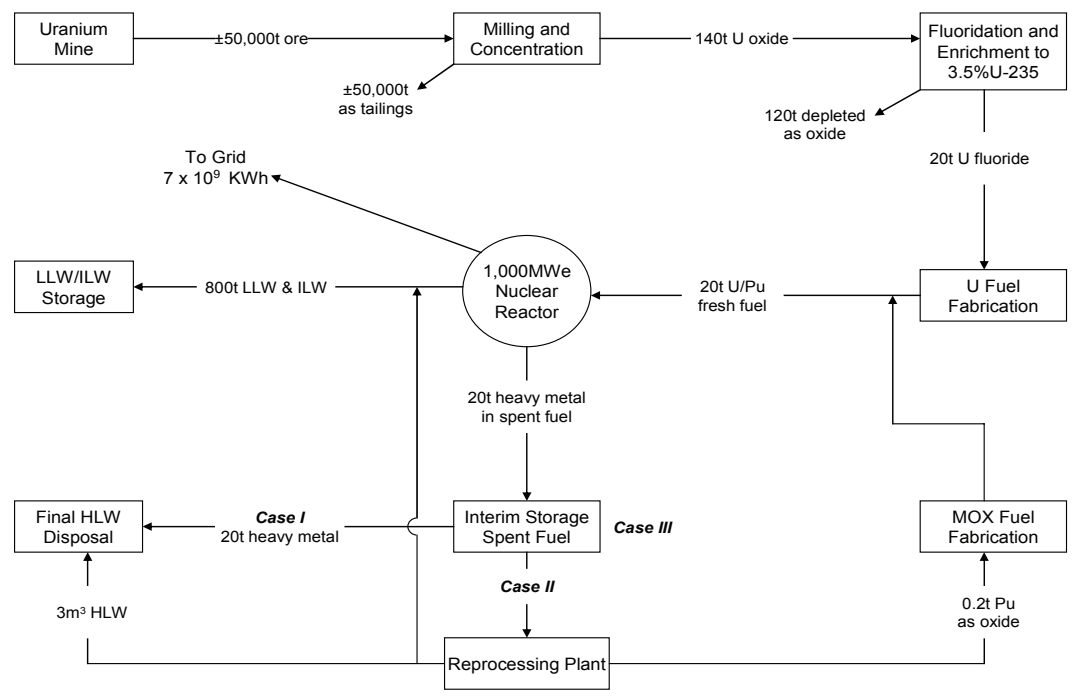

Figure 2: The nuclear fuel cycle [16, adapted]

The diagram shows the approximate annual flows of materials for the operation of a 1,000-MWe LWR. Case I represents a direct disposal or once-through fuel cycle route, i.e. a route that does not include reprocessing and recycling. Case II involves a close fuel cycle route, i.e. a route that involves reprocessing and recycling. Case III is simply long-term interim storage for as long as a decision has not been made 
about which of the two routes to follow.

Many countries have been able to generate national policies and strategies to address their respective radwaste issues. They have based their policies and strategies for SFM essentially on the above three available basic courses of action [2]:

- $\quad$ Closed fuel cycle (or reprocessing route): this involves reprocessing of SF to recover $\mathrm{U}$ and $\mathrm{Pu}$ for re-use, and treatment and conditioning of waste streams (fission products and metal) for disposal.

- $\quad$ Once-through fuel cycle (or direct disposal route): SF is suitably conditioned after a sufficient decay and cooling period and directly disposed of, with no recovery of fissile components.

- Deferral of a final decision, involving continued interim storage of SF while keeping options open.

Until the early 1990s, the world was divided into two camps over policies and strategies for dealing with SF discharged from nuclear reactors. On the one hand, many governments and utilities were committed to reprocessing their SF, ostensibly for re-using the Pu thus obtained for fast breeder reactors (FBRs) and/or mixed oxide (MOX) fuel. These included France, UK and Russia at a national level, as well as individual utilities in a number of Western European countries (Germany, Switzerland, the Netherlands, Belgium and Spain) plus Japan, which contracted most of their fuel to be reprocessed at La Hague (France) or Sellafield (UK). State utilities in many Eastern European countries also contracted their SF to be reprocessed in Russian facilities. On the other hand, a number of developed countries, including Canada, the US, Sweden and Finland, were committed to storing their SF with a long-term view to disposing of the fuels in DGR. Their reasons included nuclear proliferation concerns, technical difficulties with early reprocessing facilities and the unfavourable economics thereof, as well as environmental concerns over the large scale of nuclide discharges resulting from reprocessing operations [17], [18].

The Radioactive Waste Management Policy and Strategy for South Africa [12] calls for systematic evaluation of the merits and demerits of each of the available SFM options and identification of the best available technology not entailing excessive cost, using cost-effectiveness, technological status, operational safety, sustainable development, and social and environmental factors as the applicable assessment criteria. According to this national policy, investigations must be confined to the three principal options available internationally: reprocessing and recycling, direct disposal, and long-term (indefinite) storage.

\section{RESEARCH METHODOLOGY}

Because of the subjective nature of the SFM topic, the research methodology followed in this study is based on qualitative research methods. These methods are used to verify and validate a proposed framework for evaluating SFM options in the South African nuclear power generation context, in order to identify a preferred option for South Africa. Though producing subjective measures, the methods have been used in previous research studies where they showed significant correlation 
between subjective assessments and objective measurements [19], [20]. Also, exploring the range and nature of views is more important than the extent to which they occur in the population of interest, which is the realm of quantitative inquiry [21].

As illustrated in Figure 3, the research methodology for this study is a step-wise approach consisting of a number of research methods and expected outputs. It involves the use of several sources of data: literature research, case study, survey using a structured questionnaire, and in-depth interviews. All the methods complemented each other since none of them could alone provide comprehensive data for reliable analysis of the options.

\subsection{Literature research}

The literature research conducted in this study [22] provided useful data, facts, and analysis of SFM policies in various countries. The literature data have been significantly useful in establishing a theoretical framework with a set of assessment criteria, providing background on the issues surrounding SFM and factors influencing policy decisions, as well as formulating a theoretical prediction of the preferred option for SFM. The literature data, however, are historical and theoretical in nature, and thus the use of them alone can be misleading in terms of accurately predicting a preferred option for SFM that is specific to the South African context. Empirical data would, therefore, be required to verify and validate the robustness (strength) of the theoretical framework, and thus the accuracy and appropriateness of the theoretical predictions.

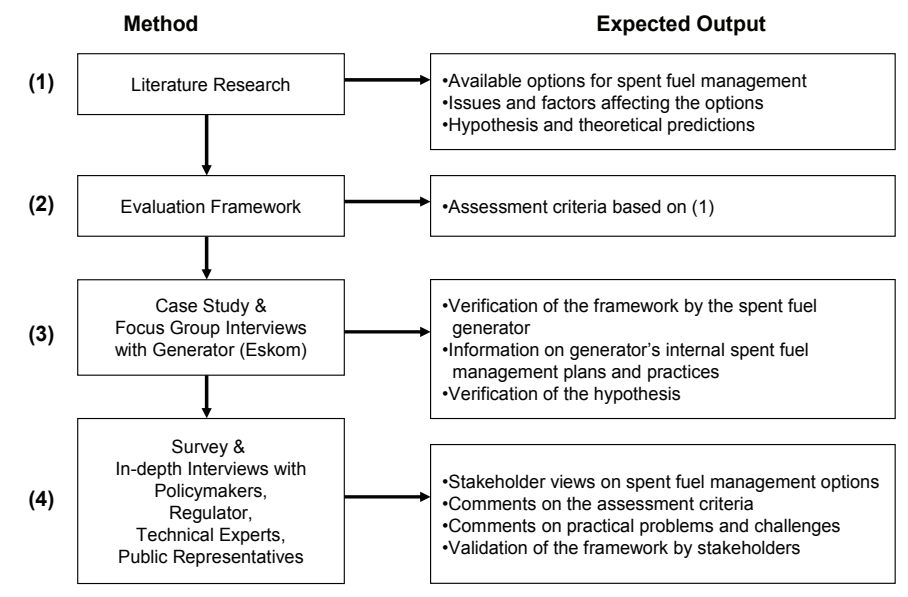

Figure 3: Research methodology structure [22]

\subsection{Case study}

One of the ways to obtain empirical data on SFM to complement the literature research data was by means of a case study, which is an appropriate empirical 
enquiry into a complex phenomenon [23]. The need for a case study emerged from the desire to investigate and understand the complex dynamics of SFM within its real-life context. Thus the management of SF generated by the Koeberg nuclear power station was used as a case study. The purpose of the case study was to establish and understand how SF is managed by Eskom as the chief generator of SF in South Africa; why a particular strategy for SFM is preferred to others; what the issues surrounding SFM at Eskom are; and in what specific ways SFM standards and criteria influence strategies. The objective of the case study was to verify the robustness of the framework and the accuracy of the theoretical predictions.

The case study approach involved discussion with a number of Eskom experts on the subject in a focus group setting, and analysis of Eskom's documents on SFM. The group of Eskom experts was invited on the basis of their direct involvement with the nuclear fuel cycle and SFM functions of the organisation. The goal of this focus group approach was to create an opportunity for dialogue about the various considerations and issues concerning SFM in Eskom, and about how their policies and strategies are being implemented. It was intended to explore a range of opinions from the experts and to interact with them in order to develop more insights and deeper understanding than could be gained in the literature research. The focus group technique was adopted for its appropriateness for the qualitative part of this study, and is comprehensively described as a useful research tool by several researchers [24], [25], [26].

The case study was structured as follows [22]:

- It consisted of seven participants who were directly involved in the nuclear fuel cycle and SFM.

- It was conducted at an Eskom venue with the necessary facilities for focus group research.

- A qualified moderator guided the discussion to explore the opinions of the participants regarding the topic of the study.

- $\quad$ A case study protocol was developed to guide the discussion, to elicit both general and specific information from the experts regarding the development of Eskom policy and strategy for SFM, and to ensure the reliability of the approach.

- $\quad$ Two sessions were arranged on different days, and both were recorded via audio (digital dictaphone) with the permission of the participants. The first session was designed to stimulate the ideas, and the second session to consolidate the discussion and reach consensus on some of the issues that were misunderstood in the previous session.

The focus group exercise led to the formulation of a questionnaire that was used in a survey. Furthermore, as part of the case study, Eskom's documents on SFM were studied and analysed.

\subsection{Survey}

The empirical data from the case study was appropriate in that it created a basis for further analysis. However, it was also important to ensure the external validity of the framework, since the purpose of this study is to establish a preferred option for 
South Africa - not for Eskom. This required that the empirical inquiry be extended to the South African population in the form of a survey, using a questionnaire as the measuring instrument. The survey was structured as follows:

\subsubsection{Questionnaire}

A questionnaire was developed with the aid of the case study focus group as a measuring instrument to elicit primary data from the population of SFM stakeholders. The questionnaire includes a description of the SFM options as a background, and is structured around a set of defined criteria or dimensions of the evaluation framework, each consisting of a number of sub-criteria that are also defined.

Two sets of questions were developed for the questionnaire. The first set of questions focused on establishing the relevance of the criteria for assessing the SFM options. The respondents were required to rate each sub-criterion on a three-point scale, where 1 means least relevant, 2 means relevant and 3 means most relevant. The reason for selecting the three-point scale was to generate extreme views represented by the two opposite ends of the scale, and to allow for moderate or central views, if any, to be represented by the middle of the scale. The second set of questions sought to determine the favourability of each SFM option as a preferred solution for South Africa in terms of the framework criteria. The respondents were required to rate each sub-criterion on a three-point scale, where 1 means least favourable, 2 means favourable and 3 means most favourable. Again, the threepoint scale was selected to produce extreme and central opinions. In each case, the results were then averaged out to yield an overall rating of the options in terms of the main assessment criterion or dimension.

\subsubsection{Sample}

A purposive heterogeneity sampling, commonly used in qualitative research [21], [27], [28], was carried out on a diverse range of participants. The participants were chosen on the basis of their specific characteristics or particular features that would enable detailed exploration of the objectives of this research. Stakeholders of the South African nuclear industry were targeted for the sampling based on their diverse roles and interests in the nuclear affairs of the country, including radwaste and SFM.

The reason for using this sampling method was because the primary interest of this part of the study lay in soliciting a broad spectrum of ideas; and, because of resource constraints, it is more practical to sample respondents for qualitative data capture purposively. It is not possible to draw general statistical inferences from this kind of sampling method, since with a purposive non-probability sample the number of people surveyed and/or interviewed is less important than the criteria used to select them [28]. Furthermore, according to Black [27], the resulting sample from a purposive sampling cannot be expected to be completely representative owing to the potential subjectivity of the researcher and the available group from which the sample is drawn. Moreover, when sampling for heterogeneity, the goal is to include all opinions or views, not to represent these views proportionately [28]. 


\subsubsection{Interviews}

The survey was reinforced with a number of follow-up in-depth interviews, as suggested by Hancock [24] and Cooper and Schindler [29], with key individuals or experts in the above sampling sectors who are highly knowledgeable and experienced in some areas of radwaste and SFM. This exercise was important for complementing and validating the above approaches, deriving a greater degree of detail than the survey data, and seeking backup of acknowledged experts in this field for the methods followed.

\section{EVALUATION FRAMEWORK FOR SPENT FUEL MANAGEMENT OPTIONS}

\subsection{Derivation and structure of the proposed evaluation framework}

A number of specific themes emerged from the issues surrounding the different SFM options highlighted in the preceding discussion, and these have formed the dimensions and criteria for assessing the options, which are basically components of a structured evaluation framework. These can be rationalised as follows:

- $\quad$ Technological: All SFM options that have been reviewed, particularly the three being pursued in this study, depend on a number of technologies at their various stages of implementation. The reprocessing and recycling option depends on the reprocessing, waste conditioning, transportation, storage, and disposal technologies. The direct disposal option relies on storage, transportation, encapsulation, and disposal technologies. The indefinite storage option currently depends on storage and transportation technologies, and could eventually include a disposal technology. It surfaced in the review that some options are not currently adopted because the technologies involved are not yet mature or available, while others are based on capital intensive technologies that are currently not affordable for some countries. These and other technological considerations are thus important in the evaluation and choice of options. Hence technology is proposed as an assessment criterion for the evaluation of the SFM options.

Environmental: In the review of the issues surrounding the SFM options, it was observed that an SFM would be either attractive or unattractive as a choice on the basis of its environmental performance. For example, the reprocessing and recycling option has been severely criticised for the environmental pollution resulting from the reprocessing, conditioning, and MOX fuel fabrication processes. The respective environmental impacts of direct disposal and indefinite storage have also been noted. Hence the environmental consideration is proposed as an assessment criterion for the evaluation of the SFM options.

- Safety: Safety is always of primary consideration in the choice of nuclear options. In the literature review, all SFM options have been either supported or criticised on the basis of their respective short- and long-term safety impacts, e.g., the long-term safety of the storage facilities in the indefinite storage option. Safety is, therefore, a compelling criterion to be considered in the evaluation the SFM options. 
- Non-proliferation: As revealed in the literature review, for some countries, such as the US, non-proliferation considerations significantly influenced the change of their nuclear fuel cycle policies. So, for as long as SFM deals with fissile material such as Pu, the choice of a suitable SFM option will consider issues of non-proliferation.

- Economic: Economic considerations, according to the literature review, have also been influential in the selection of a nuclear fuel cycle policy in different countries. For instance, Finland and Sweden abandoned the reprocessing and recycling option and pursued the direct disposal option on economic grounds, while Japan and France rely heavily on the reprocessing and recycling option for energy security reasons. As a result, economics is also important for the evaluation and selection of SFM options.

- Security: Physical security has also been highlighted as an important consideration in the literature review, particularly in relation to transport and storage facilities. Although it is linked with non-proliferation, physical security must be considered separately as an evaluation parameter, because a security threat is posed not only by the involvement of fissile material but also by non-nuclear activities aimed at harming nuclear installations and humans, e.g., deliberate aircraft crashes. Thus a suitable SFM option would be the one in which the security threat is perceived to be minimal in comparison with other options.

- Sociopolitical: The debates covered in the literature review have largely been sociopolitical. It has been observed that the different SFM options or their elements have not received either public acceptance or political support upon their selection or implementation. Therefore, sociopolitical consideration is important in the evaluation of the SFM options.

- $\quad$ Ethical: Issues about intergenerational and intragenerational equity have stood out in the literature survey. All three SFM options are in one way or another being questioned or criticised in terms of the ethical considerations for current and future generations. Only an option with high ethical values can thus be considered attractive. Ethical consideration is thus important in the evaluation of the different SFM options.

- Institutional: It has been shown in the literature review that the different options are governed or implemented in terms of the institutional framework of the country. In Switzerland, for example, reprocessing and recycling remains an option, but the direct disposal option is set to be promoted in the new version of the Swiss atomic law, which is indicative of a strong institutional capacity; while in the UK, government and utilities are disillusioned with reprocessing and with the service provider, BNFL, which is indicative of a weak institutional relation. Therefore, the different options need to be assessed in terms of the strength, capability, and capacity of the institutional (government, legal, regulatory, organisational) framework to provide direction in the implementation of the options.

It is accepted that the above list may not be exhaustive or comprehensive: there 
may be other possible dimensions or criteria that are embedded within or are external to this list, even though they were not specifically highlighted in the literature review. These could include, for example, the commercial criterion (e.g. investment in a SFM option with the aim of making a profit, or the commercial competitiveness of nuclear power as a source of electricity), or funding (e.g. financing of the systems to be put in place, or a fund necessary to guarantee implementation of the options). However, at this stage the above set of criteria is taken as the point of departure for the evaluation of the SFM options, because it has emerged directly from the literature review (although it is still to be verified and validated). Therefore a framework for the evaluation of SFM options incorporating this set of criteria is proposed. It is schematically shown in Figure 4.

\subsection{Verification and validation of the proposed evaluation framework}

The proposed framework was subjected to verification and validation processes, described in detail in the author's thesis [22], which led to a consolidated, comprehensive structure (Figure 5). The construction of this framework was aided by the adoption of a qualitative approach, as described in the research methodology section above.

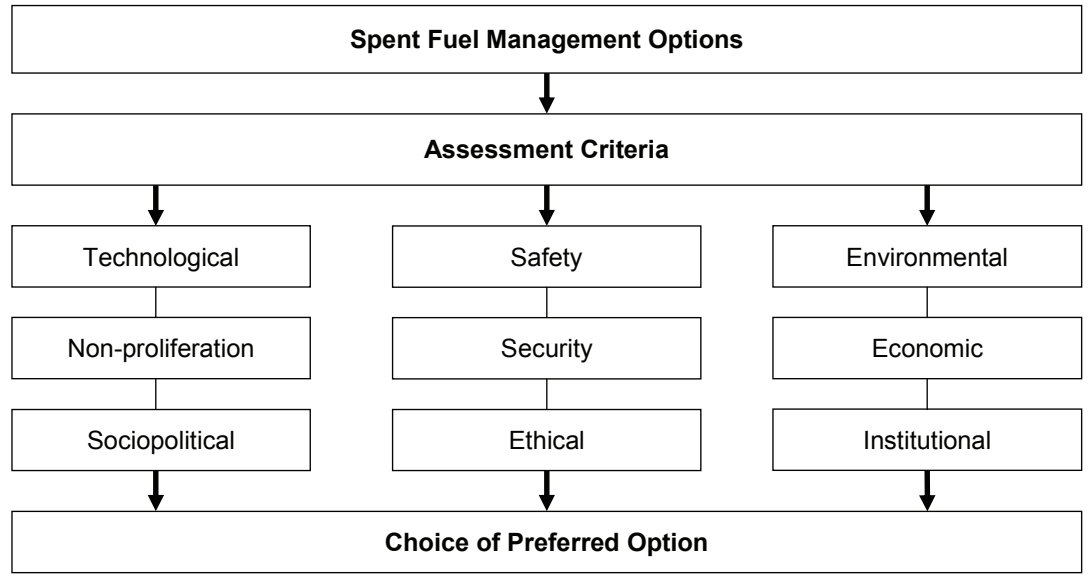

Figure 4: Proposed evaluation framework [22] 


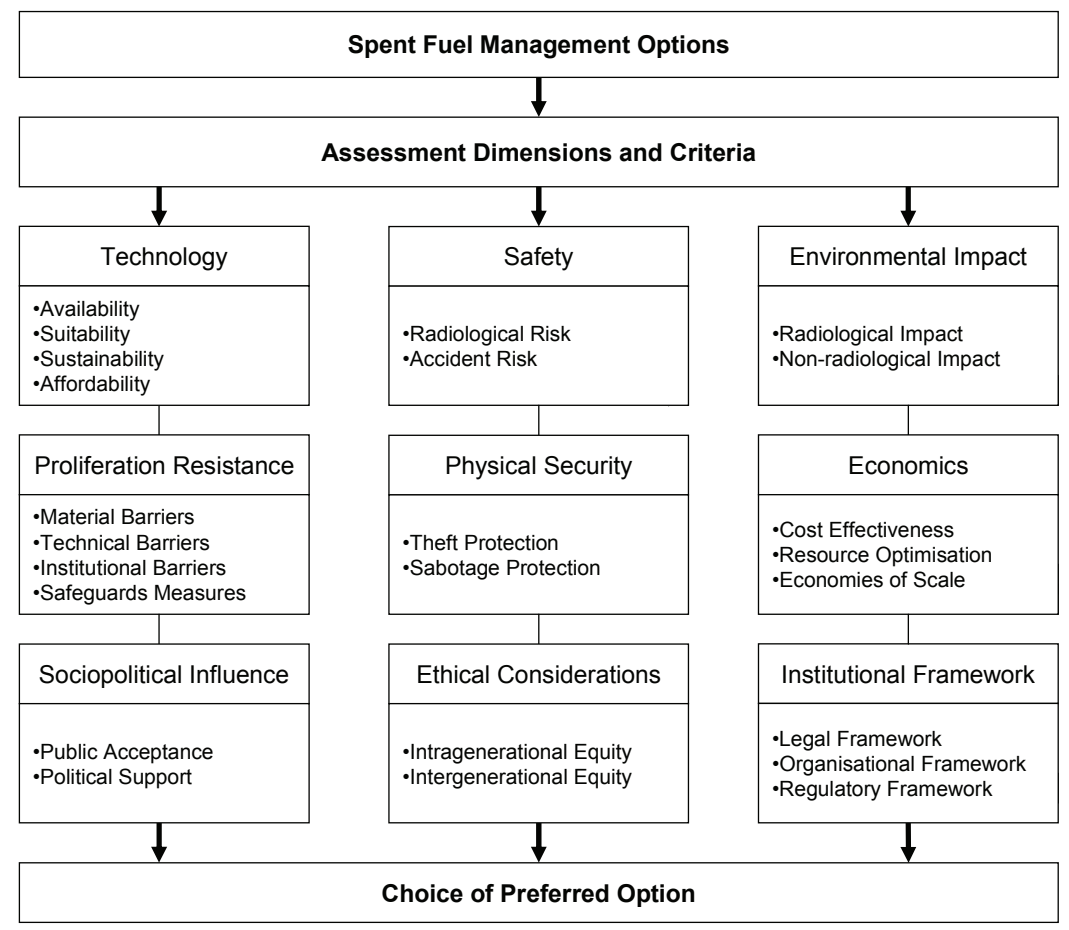

Figure 5: Validated framework for evaluating spent fuel management options [22]

The case study that was conducted on Eskom's SFM was useful in verifying the proposed framework. It resulted in a more comprehensive framework that incorporates relevant dimensions and sets of criteria for assessing the SFM options. It was also useful to generate empirical assessment data to complement the literature research data upon which the proposed framework is based, since the need for the case study arose from the desire to investigate and understand the complex dynamics of SFM within a real-life context. Hence, it is concluded that Eskom has a comprehensive SFM policy and strategy, from discharge of SF from the reactor through to its final disposal underground. As the Eskom reference SFM strategy is based on the direct disposal option, a basis for the comparison of this option with the other SFM options using the verified framework with its sets of assessment criteria is thus provided.

The validation process, on the other hand, indicated that all assessment criteria in the framework for evaluation of SFM options are relevant. Some of the criteria, however, were not considered completely relevant by some of the survey respondents, and reasons were offered for the opposing views. Nevertheless, such criteria are deemed relevant overall owing to their endorsement by the majority of 
the respondents, with counter reasons given. Ultimately, it was concluded that the verified framework is relevant to the evaluation of SFM options, and is thus valid for the analysis of the options (which will be discussed in a future paper).

\subsection{Evaluation dimensions and criteria}

The following is a brief description of the components of the developed evaluation framework as verified and validated. These components are basically the dimensions and criteria for evaluating the SFM options.

\subsubsection{Technology}

Any SFM option will certainly rely on some technology at one or more stages of its implementation. A desired SFM technology would have characteristics that define the technology. Some of the characteristics can be viewed as positive or advantageous (e.g., as benefits) and others as negative or disadvantageous (e.g., as costs). The choice of one technology over others would, therefore, be greatly influenced by the balance between its positive and negative characteristics. In this case, availability, suitability, sustainability, and affordability were identified as the technology characteristics or criteria for the evaluation of the SFM options. These criteria are defined as follows:

- $\quad$ Availability: “A desired SFM option should be based on an available, proven technology that satisfies both technical and regulatory requirements."

- $\quad$ Suitability: "A desired SFM option should be based on a technology that is fit for purpose in terms of operability, maintainability, reliability, and compatibility with existing systems and country-specific conditions."

- $\quad$ Sustainability: "A desired SFM option should be based on a technology that does not contribute to human displacement, resource depletion, or increased environmental pollution but that makes use of locally available skills, tools, and materials."

- Affordability: "A desired SFM option should be based on a technology, the cost of which does not impose undue economic hardship on the country, compromise safety considerations, or displace other essential activities of the country's SFM programme."

\subsubsection{Safety}

A preferred SFM option would be that which 'best' meets the requirements for safe SFM to protect human health and the environment at any given time. These safety requirements would have to be met during and after the operation and closure of the SFM facilities, as well as in the transportation of SF or radwaste. They would be based on national and international safety principles, standards and guidelines, as well as on international experience in the development and operation of SFM systems. Radiological and accident risks were considered as the most relevant safety criteria for evaluating the SFM options under study. These criteria are defined as follows:

- $\quad$ Radiological risk: “A desired SFM option should have low radiological risks and high protection against radionuclide releases to the environment and 
radiation doses to the members of the public during the normal operation of the facilities and transportation."

- $\quad$ Accident risk: "A desired SFM option should have low accident risks and high defense-in-depth so that the probability of a severe accident leading to offsite releases is kept very small, and the consequences of such releases, should they occur, are limited."

\subsubsection{Environmental impact}

An SFM option will face environmental challenges that prevail throughout the siting, operation, and post-closure of the SFM facilities, and that impact on environmental and natural resources directly or indirectly relating to the public's health and welfare. The greatest challenge, therefore, would be to ensure mitigation of these impacts. In this study, radiological and non-radiological impacts are identified as the environmental characteristics or criteria for the evaluation of SFM options. These criteria are defined as follows:

- $\quad$ Radiological impact: “A desired SFM option should have a low possibility of direct ionising radiation exposures to workers and the public in the vicinity of SFM facilities and transportation routes."

- Non-radiological impact: "A desired SFM option should have minimal nonradiological effects such as traffic, noise, visual amenity, disturbance of natural habitats, restrictions on land use, or social and economic factors that may arise during construction, operation and decommissioning of facilities and during transportation."

\subsubsection{Proliferation resistance}

An SFM option must be proliferation resistant. Proliferation resistance is "that characteristic of a nuclear energy (or fuel cycle) system that impedes the diversion or undeclared production of nuclear material, or misuse of technology, by States in order to acquire nuclear weapons or other explosive devices". The degree of proliferation resistance results from a combination of technical design features, operational modalities, institutional arrangements, and safeguards measures. In this study, material barrier, technical barrier, institutional barrier, and safeguards measures are identified as the non-proliferation characteristics or criteria for the evaluation of SFM options. These criteria are defined as follows:

- Material barrier: “A desired SFM option should have high proliferation resistance in terms of the inherent properties of the nuclear material involved that would make it difficult to extract weapons-useable material and to design and construct a weapon."

- Technical barrier: "A desired SFM option should have high proliferation resistance in terms of the technical design features of the SFM systems involved that would deter unwarranted access to weapons-usable materials and/or misuse of facilities for proliferation agendas."

- Institutional barrier: "A desired SFM option should have high proliferation resistance in terms of the institutional non-proliferation measures and instruments, such as a State's decisions on nuclear energy systems, including conventions, treaties, bilateral/multinational agreements, national policies 
and legislation, and societal openness and transparency."

- $\quad$ Safeguards measures: "A desired SFM option should have high proliferation resistance in terms of accounting for, controlling the use of, and minimizing the risk of early detection of nuclear materials in order to deter their diversion from peaceful use."

\subsubsection{Physical security}

An SFM option will require physical protection against the theft of valuable materials and/or equipment in SFM facilities, excluding proliferation as a motivating force, and against sabotage of the facilities by political or terrorist activities. In this study, theft protection and sabotage protection are identified as the physical security characteristics or criteria for the evaluation of SFM options. These criteria are defined as follows:

- $\quad$ Theft protection: “A desired SFM option should have high physical security against theft of valuable materials and/or equipment in SFM facilities and during transportation through use of protective measures, including surveillance and security guards."

- Sabotage protection: "A desired SFM option should have high physical security against any act of sabotage on an SFM facility and/or transport, as it could create a radiological hazard to the personnel, and a potential radioactive release to the public and the environment."

\subsubsection{Economics}

An SFM option must be economically viable. The relative costs required to achieve a complete life cycle of SFM need not be excessive. Contribution of the option in the optimisation and conservation of uranium as a nuclear energy resource should be taken into account since uranium, like fossil fuels, becomes more expensive as supplies are depleted, and thus its cost affects the relative economics of nuclear fuel cycle schemes upon which SFM options are based. In this study, costeffectiveness, resource optimization, and economies of scale are identified as the economic characteristics or criteria for the evaluation of SFM options. These criteria are defined as follows:

- Cost effectiveness: “A desired SFM option should have reasonably low relative cost needed to achieve a complete life cycle of SFM, including investment, operation, transportation, and decommissioning costs."

- $\quad$ Resource optimisation: "A desired SFM option should contribute to resource optimisation and conservation in the broader context of national energy security and the socioeconomic situation."

- Economies of scale: "A desired SFM option should have high positive economies of scale with an increase in the volume of the SF inventory to be managed by the SFM systems, resulting in a decrease in the average fixed cost of each unit of the inventory."

\subsubsection{Socio-political influence}

An SFM option will be influenced by socio-political aspects. The ultimate target of 
SFM is the construction of facilities for safe treatment, storage, and final disposal of spent fuel and/or radwaste; but in most countries this is not possible without political consensus and public acceptance. In this study, public acceptance and political consensus are identified as the socio-political characteristics or criteria for the evaluation of SFM options. These criteria are defined as follows:

- $\quad$ Public acceptance: “A desired SFM option should receive high public acceptance depending on the perceived risks associated with the types, volumes, and toxicity of wastes to be managed, and the types of SFM facilities and their deployment approach."

- $\quad$ Political support: "A desired SFM option should have high political support based on a broad array of policy concerns, public response, and the rationality underlying determination of risk acceptability."

\subsubsection{Ethical considerations}

An SFM option must incorporate ethical principles that include fairness and equity and show that responsibilities for current and future generations can be met. In this study, intergenerational equity and intragenerational equity are identified as the ethical characteristics or criteria for the evaluation of SFM options. These criteria are defined as follows:

- Intragenerational equity: "A desired SFM option should show great fairness and equity to the present generation by balancing resource allocation and involving various sections of contemporary society in a fair and open decision-making process related to SFM."

- Intergenerational equity: "A desired SFM option should show great fairness and equity to future generations by enabling the current generation to avoid leaving potential risks and burdens to future generations."

\subsubsection{Institutional framework}

An SFM option will largely depend on a robust framework of institutions to carry out management and regulatory responsibilities. In this study, legal framework, organisational framework, and regulatory framework are identified as the institutional characteristics or criteria for the evaluation of SFM options. These criteria are defined as follows:

- Legal framework: "A desired SFM option should match the capability of the existing legal regime so that the necessary statutory control over the management of the option can be adequately exercised."

- Organisational framework: "A desired SFM option should match the organisational capability for effective management of SFM facilities, as the more complex and sophisticated the facilities are, the greater the organisational and management demands for effective management will be." 
Regulatory framework: "A desired SFM option should match the regulatory capability to ensure the safety of workers and the public and the protection of the environment through effective control over the safety conditions and environmental impact of the facilities."

\section{CONCLUSION}

The field of SFM has been explored in this study and found to be a component of nuclear technology that is extremely complex and controversial in nature. It is surrounded by highly contentious issues, and is receiving growing attention as the inventories of SF, along with the plutonium and high-level radioactive waste derived from the reprocessing of SF, continue to accumulate worldwide. A number of options for the management of the inventories are available - some matured and put into practice, and others still under research and development. Three available options for SFM currently adopted as SFM policy by different countries are reprocessing and recycling, direct disposal, and indefinite storage. All three options have their technical merits, but they are also contentious in various degrees both within the nuclear industry and in the public domain.

The research methodology for this study is based on the qualitative approach, which involves qualitative research methods that yield subjective measures of people's opinions. These methods have been used in previous research studies, which have shown a correlation between subjective assessments and objective measurements. Literature research, a case study approach, and a survey based on purposive heterogeneity sampling with follow-up interviews have been used to complement each other and to verify and validate the proposed evaluation framework. It is concluded that this methodological approach is capable of producing the desired framework for evaluating SFM options, which can also be verified and validated.

Through the implementation of the methodological approach followed in this study, at least nine categories of issues have been identified as factors affecting the SFM options: technology, safety, environmental impact, proliferation resistance, physical security, economics, sociopolitical influence, ethical principles, and institutional capability. These formed the evaluation framework and were used as the criteria to assess the SFM options for the South African context. A more detailed discussion of validation and application of this framework to evaluate the SFM options and derive a preferred option for South Africa will be the subject of a future paper.

Despite the contentious issues surrounding SFM, the study has shown that the three available options for SFM have developed to a stage where countries, including South Africa, can make an informed policy decision on the strategy they wish to pursue. The choice between the SFM options is thus a matter of national policy, not one made by the nuclear industry in isolation from the public and government. In fact, the choice between the options involves strategic/political, economic, and technical issues, and as the strategic/political issues often are the most important, the choice is often made by government.

The overarching conclusion, however, is that this study uncovers at least the qualitative considerations for SFM. These should considerably promote the development of a rational response to the vexing question of radioactive waste 
management in South Africa. This study has also been able to introduce and develop new knowledge on the strategic management of spent nuclear fuel produced by the nuclear industry in South Africa. A perspective on a topic that has been raised as a concern but that has not been systematically and comprehensively addressed in South Africa is offered. Simultaneously, it should prepare the South African nuclear energy sector and its stakeholders for the challenges brought about by radioactive waste management.

\section{REFERENCES}

[1] Blumenthal, A., Lindeman, E. 1995. Handbook: The International Nuclear Fuel Cycle. Background and issues: The debate over spent nuclear fuel disposal and civilian plutonium recycle, New York Nuclear Corporation (NYNCO), USA, 1995.

[2] IAEA. 1995. 'Options, experience and trends in spent nuclear fuel management', Technical Reports Series No.378, International Atomic Energy Agency, Vienna, June 1995.

[3] IAEA. 2005. 'Technical, economic and institutional aspects of regional spent fuel storage facilities', IAEA-TECDOC-1482, International Atomic Energy Agency, Vienna, Austria, 2005.

[4] Posiva. 1999. 'The final disposal facility for spent nuclear fuel', Environmental Impact Assessment Report, Posiva Oy, Finland, 1999.

[5] McCombie, C. 2003. 'International perspectives on the reprocessing, storage, and disposal of spent nuclear fuel', National Academy of Engineering, The Bridge, Volume 33, Number 3, Fall 2003.

[6] Ruchkin, S.V., Loginov, V.Y. 2006. 'Securing the nuclear fuel cycle: What next?', IAEA Bulletin 48/1, September 2006. [Online] www.iaea.org/Publications/Magazines/Bulletin/Bull481/pdfs/rushkin.pdf

[7] Bechthold, W., Closs, KD., Knapp, U., Papp R. 1987. 'Direct disposal of spent nuclear fuel', Radioactive Waste Management Series, Published by Graham \& Trotman for the Commission of the European Communities, June 1987.

[8] Bunn, M., Holdren, J.P., Wier, A. 2002. 'Securing nuclear weapons and materials: Seven steps for immediate action', Project on Managing the Atom, Belfer Center for Science and International Affairs, John F. Kennedy School of Government, Harvard University, 2002.

[9] IAEA. 2003. 'Country nuclear power profiles', 2003 edition [On line]. Accessed on 22 August 2007, http://www.pub.iaea.org/MTCD/publications/PDF/cnpp2003/CNPP_Webpag e /PDF/2003/index.htm

[10] Wallner, M., Bräuer, V. 2001. 'Nuclear waste disposal in Germany: Background, status and future research', Chapter 13 of Geological 
challenges in radioactive waste isolation, Third worldwide review, edited by P.A. Witherspoon \& G.S. Bodvarsson, Berkeley, California. Prepared for the US-DOE, December 2001.

[11] Neerdael, B., Volckaert, G. 2001. 'The Belgium RD\&D program on long-lived and high-level waste disposal: Status and trends', Chapter 5 of Geological challenges in radioactive waste isolation, Third worldwide review, edited by P.A. Witherspoon \& G.S. Bodvarsson, Berkeley, California. Prepared for the US-DOE, December 2001.

[12] DME. 2005. 'Radioactive waste management policy and strategy for the Republic of South Africa', Department of Minerals and Energy, South Africa, November 2005. [On line]

http://www.dme.gov.za/pdfs/energy/nuclear/radwaste_policy_2005.pdf

[13] IAEA. 1992. Radioactive waste management: An IAEA source book, International Atomic Energy Agency, Vienna, July 1992.

[14] Cogema. 2001. 'Evaluating the reprocessing, conditioning \& recycling (RCR) programme for the management of Koeberg spent fuel', Cogema (now Areva NC) presentation to Eskom and DME, Johannesburg, 5-6 December 2001.

[15] NEA. 1984. Geological disposal of radioactive waste, Nuclear Energy Agency, OECD, Paris, France, 1984.

[16] Beck, P. 1994. Prospects and strategies for nuclear power: Global boon or dangerous diversion?, The Royal Institute of International Affairs, London, 1994.

[17] Fairlie, I. 2000. 'Dry storage of spent nuclear fuel: The safer alternative to reprocessing'. Report to Greenpeace International in response to Cogema dossiers to the La Hague Public Inquiry, May 2000.

[18] Berkhout, F. 1991. Radioactive waste: Politics and technology, Routledge, London and New York, 1991.

[19] Oosthuizen, H. 2005. 'The relationship between strategic process dimensions and organisational output performance - A South African investigation in relation to global practices', South African Journal of Business Management, Vol.36, No.4, pp. 69-79, 2005.

[20] Duncan, I.J. 1999. 'Some aspects of the relationship between society and the disposal of radioactive waste', The Uranium Institute 24th Annual Symposium, London, 8-10 September 1999.

[21] National Statistics. 2006. About National Statistics \& ONS, Data Collection Methodology (DCM) Services - Purposive Sampling, UK National Statistics, [On-line], www.statistics.gov.uk/about/services/dcm/sampling.asp. Viewed on 20 October 2006.

[22] Twala, V.G. 2007. Evaluation of spent nuclear fuel management options for South Africa, Thesis presented in partial fulfilment of the requirements for 
the Degree of Doctor Philosophiae in Engineering Management in the Faculty of Engineering and the Built Environment, University of Johannesburg, September 2007.

[23] Yin, R. 2003. Case study research: Design and methods, $3^{\text {rd }}$ edition, Thousand Oaks, California, Sage Publications, 2003.

[24] Hancock, B. 2002. An introduction to qualitative research, Trent Focus Group, 2002.

[25] Hesse-Biber, S.N., Leavy, P. 2004. Approaches to qualitative research: A reader on theory and practice, Oxford University Press, New York, 2004.

[26] Labuschagne, C. 2005. Sustainable project life cycle management: Development of social criteria for decision-making, Doctoral thesis, Department of Engineering \& Technology Management, University of Pretoria, May 2005.

[27] Black, T.R. 1999. Doing quantitative research in the social sciences: An integrated approach to research design, measurement and statistics, Sage Publications, London, California, New Delhi, 1999.

[28] Trochim, W.M.K. 2006. 'Nonprobability sampling', Research Methods Knowledge Base, [On-line]

http://www.socialresearchmethods.net/kb/sampnon.htm. Viewed on 20 October 2006.

[29] Cooper, D.R., Schindler, P.S. 2006, Business research methods, $9^{\text {th }}$ edition, McGraw-Hill. 